\title{
Case Report: Fatal Abdominal Stabbing: A Confusing Picture in Differentiating Homicide and Suicide
}

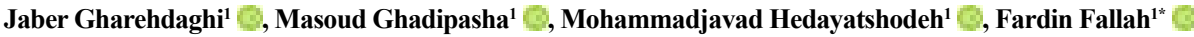

1. Legal Medicine Research Center, Legal Medicine Organization, Tehran, Iran.

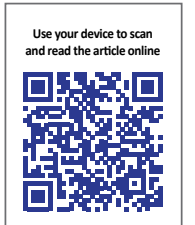

Citation: Gharehdaghi J, Ghadipasha M, Hedayatshodeh M, Fallah F. Fatal Abdominal Stabbing: A Confusing Picture in Differentiating Homicide and Suicide. International Journal of Medical Toxicology and Forensic Medicine. 2019; 9(3):155-158. https://doi.org/10.32598/ijmtfm.v9i3.25260

https://doi.org/10.32598/ijmtfm.v9i3.25260

(A) 08

Article info:

Received: 03 Jan 2019

First Revision: 26 Jan 2019

Accepted: 13 May 2019

Published: 01 Jul 2019

\section{Keywords:}

Abdomen, Homicide, Injury, Stab wound, Suicide

\begin{abstract}
A B S T R ACT
Background: Differentiating between homicide and suicide can be difficult and even impossible. In this report, we presented a fatal stabbing injury, which made a challenge in the verification of the manner of death.

Case Report: A 45-year-old man was found dead in his workplace with a knife beside him His mouth was closed with a scarf, his clothes were intact, and no evidence of a struggle was observed in the scene investigation. There was a vertical stab wound on the midline of the victim's belly and his intestines were tangled out of the wound. In the autopsy, no defense wound was found. There was blood in the abdominal cavity and retroperitoneal region and several perforations were observed in the intestine and liver along the superficial wound. Painful death and torturous extraction of visceral organs resembled homicide, but nothing indicative of hostility and homicide was found by the forensic exploration and police investigation. Finally, the manner of death was assigned as suicide and the cause of death was a hemorrhagic shock as a result of sharp force injuries.
\end{abstract}

Conclusion: This case represents a bizarre suicide, which is rare and highly suspicious of homicide. In such mysterious cases, the evidence of autopsy and crime scene and police investigation should be regarded to make a decision.

\section{Introduction}

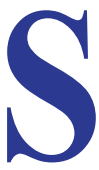

uicide is a global public health problem with considerable mortality [1]. In the field of forensic medicine and criminology, distinguishing between homicide and suicide can become a challenge [2, $3]$. Sharp force injuries are one of the confusing pictures for differentiation between suicide and homicide; in some cases, the differentiation is even im- possible [3], and misclassification may also happen [4]. Studies show that stabbing injuries are commonly used for homicide, but few reports of suicide by this method have been reported that are usually associated with psychological problems of suicide attempter $[5,6]$.

In this report, we presented a fatal abdominal stabbing injury with bizarre presentation that made a challenge in distinguishing between suicide and homicide.

* Corresponding Author:

Fardin Fallah, PhD.

Address: Legal Medicine Research Center, Legal Medicine Organization, Tehran, Iran.

Tel: +98 (21) 55983260

E-mail: fardin.fallah@gmail.com 


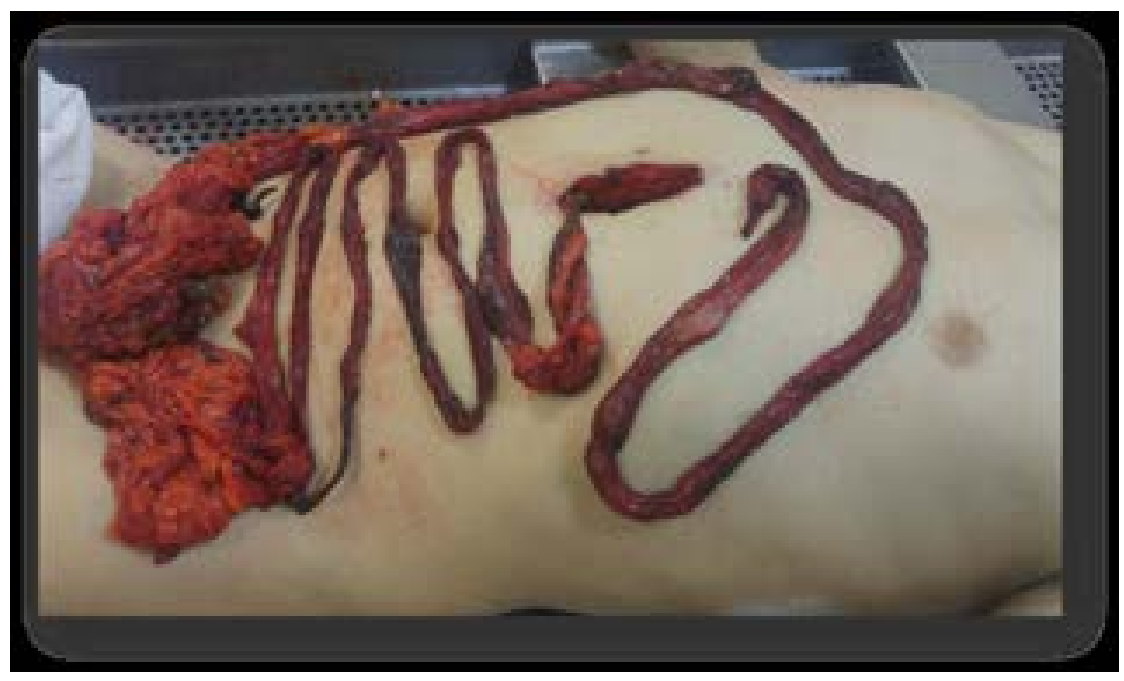

Figure 1. The general appearance of the victim

International Journal of

\section{Case Report}

A forty five-year-old Iranian man was found dead in his workplace, a shoe store. The door of the store was locked and family members of the man broke into the workplace after his long absence and they called the police. Victim's mouth was closed with a scarf, but his hands were open. He was wearing intact clothes, but there was a deep stab wound in his belly and his visceral organs were out of his body. Evidence was indicative of death 6-12 hours before finding the victim.

There was a blood pool around the victim and his hands and feet were bloody and a kitchen knife was also found beside him. At first sight, the presentation suggested homicide, but no messiness of the scene and evidence of struggle were observed. In the forensic exploration, there was nothing unnatural in the head and neck, extremities, and genital of the cadaver and no defense injury was observed. There was a vertical stab wound with the length of $7 \mathrm{~cm}$ in the midline of the body upper than umbilicus (Figure 1); $260 \mathrm{~cm}$ of the victim's intestine and mesentery were dangled out of the wound.

In the autopsy, 1 liter blood was present in the abdominal cavity and liver was ruptured by 4 stab wounds. There were also 4 perforations in the intestinal mesentery along the superficial wounds (Figure 2). Kidneys and spleen

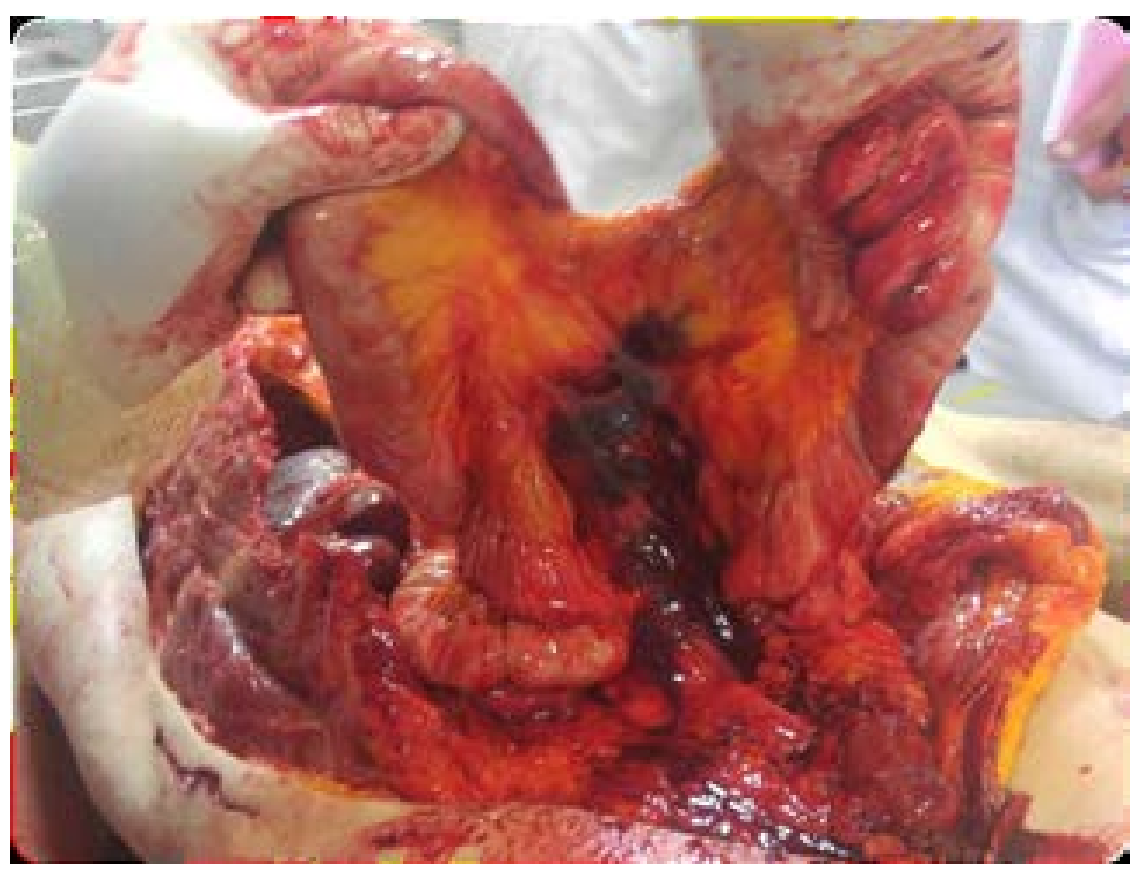

Figure 2. Intestinal ruptures of the victim 
were intact, but there were 0.5 liters blood in the retroperitoneal region. No other significant finding was observed in the autopsy. Forensic exploration revealed that superficial and visceral wounds were made by the knife found in the scene. Urine, blood, visceral, and vitreous samples were negative for drugs, toxins, and alcohol.

This case was a big challenge for the police and forensic medicine team to discern suicide and homicide. The victim was married with 5 children and had some familial conflicts, but he had no suicidal attempts beforehand. Police investigation revealed that during the incident day, the store was closed and none of the neighbors visited the victim or any other person; thus, homicide could not be confirmed. Death happened during working hours and the store was located in a crowded place; hence probable entrance of any one to the store could not be concealed from neighbors. Finally, according to the available evidence, the cause of death was assigned as a hemorrhagic shock because of sharp force injuries and the manner of death was diagnosed as suicide.

\section{Conclusion}

Comprehensive exploration with the toxicological study of the corpse, precise scene investigation in cooperation with the police, and review of the victim's medical history are all essential in distinguishing between suicide and homicide $[3,7,8]$. Nobody prefers painful death and this is a reason why we usually think of homicide in sharp force injuries [6]. Our victim must have experienced bad pain while his visceral organs were extracted from the wound. Such a picture is usually associated with hostile homicide, but the police and forensic investigations did not find anything to confirm homicide. Studies show that suicide by sharp instruments, especially by injuring the abdominal area, is not common $[3,9,10]$. However, few reports of suicide by abdominal stabbing have been reported in the literature $[2,9,11]$.

Some autopsy clues such as the presence of hesitation marks $[3,9]$ and number, as well as location and axis of cut wounds [3, 4], guide us to make a diagnosis of suicide, but none are decisive and all need complementary investigation of the scene and obtaining data about the victim's personal and social conditions [3]. In addition, the accessibility of the abdominal region for the victim, the presence of a single wound [3], open hands, and intact clothes were all in favor of suicide. We did not find hesitation marks, but studies show that hesitation wounds in abdominal self-injuries are not usually present [10] and their absence does not rule out suicide.
Interviewing with witnesses revealed that in the incident day, the store was closed and no one entered there.

The mysterious part of the event was the extraction of the intestines from the wound that resembled some kinds of torture. According to the family members' statements, the victim had no history of suicide attempts or psychological problems. Hence, the reason for choosing such a method of suicide remained unclear. It should be mentioned that many mood and mental disorders may not be diagnosed or reported in people, especially those with low socioeconomic status and this victim might have been suffering from psychological disorders that remained undiagnosed. This study reveals the necessity of integration of data from various sources in cases with dubious picture of death.

\section{Ethical Considerations}

\section{Compliance with ethical guidelines}

The identity of the victim was concealed and informed consent was obtained from family members of the victim for this report.

\section{Funding}

This paper is an original research and there is no financial support.

\section{Author's contributions}

Conceptualization, writing-review and editing: All authors; Forensic exploration and scene investigation: Masoud Ghadipasha, Fardin Fallah; Writing-original draft: Fardin Fallah; Supervision: Jaber Gharehdaghi and Masoud Ghadipasha.

\section{Conflict of interest}

The authors declared no conflict of interest.

\section{Acknowledgements}

Special thanks to police officers and victims' family members for their cooperation.

\section{References}

[1] Malakouti SK, Davoudi F, Khalid S, Asl MA, Khan MM, Alirezaei $\mathrm{N}$, et al. The epidemiology of suicide behaviors among the countries of the eastern Mediterranean region of WHO: A systematic review. Acta Medica Iranica. 2015; 53(5):257-65. 
[2] Lau M, Wu JH. Complex suicide or concealed homicide? The case of multiple stab wounds in a fatal fall from a height. Pathology. 2019; 51:S116. [DOI:10.1016/j.pathol.2018.12.330]

[3] De $\square$ Giorgio F, Lodise M, Quaranta G, Spagnolo AG, d'Aloja E, Pascali VL, et al. Suicidal or homicidal sharp force injuries? A review and critical analysis of the heterogeneity in the forensic literature. Journal of Forensic Sciences. 2015; 60:S97107. [DOI:10.1111/1556-4029.12673] [PMID]

[4] Karlsson T. Homicidal and suicidal sharp force fatalities in Stockholm, Sweden: Orientation of entrance wounds in stabs gives information in the classification. Forensic Science International. 1998; 93(1):21-32. [DOI:10.1016/S03790738(98)00025-5]

[5] Karger B, Niemeyer J, Brinkmann B. Suicides by sharp force: Typical and atypical features. International Journal of Legal Medicine. 2000; 113(5):259-62. [DOI:10.1007/s004149900093] [PMID]

[6] Singh KP, Keisham S, Rishilu K, Devi TM. Suicidal death due to stabbing: A case of rare occurrence. Journal of Indian Academy of Forensic Medicine. 2014; 36(4):434-6.

[7] Ohshima T, Kondo T. Eight cases of suicide by self-cutting or-stabbing: Consideration from medico-legal viewpoints of differentiation between suicide and homicide. Journal of Clinical Forensic Medicine. 1997; 4(3):127-32. [DOI:10.1016/ S1353-1131(97)90092-4]

[8] Fukube S, Hayashi T, Ishida Y, Kamon H, Kawaguchi M, Kimura A, et al. Retrospective study on suicidal cases by sharp force injuries. Journal of Forensic and Legal Medicine. 2008; 15(3):163-7. [DOI:10.1016/j.jflm.2007.08.006] [PMID]

[9] Byard RW, Klitte A, Gilbert JD, James RA. Clinicopathologic features of fatal self-inflicted incised and stab wounds: A 20-year study. The American Journal of Forensic Medicine and Pathology. 2002; 23(1):15-8. [DOI:10.1097/00000433200203000-00003] [PMID]

[10] Atreya A, Rijal D, Kanchan T, Shekhawat RS. Abdominal self-stabbing: A case report. Medico-Legal Journal. 2017 85(2):97-9. [DOI:10.1177/0025817216683583] [PMID]

[11] Pelletti G, Visentin S, Rago C, Cecchetto G, Montisci M. Alteration of the death scene after self-stabbing: A case of sharp force suicide disguised by the victim as a homicide? Journal Forensic Sciences. 2017; 62(5):1395-8. [DOI:10.1111/15564029.13440] [PMID] 